\title{
Galactosaemia: results of the British Paediatric Surveillance Unit study, 1988-90
}

\author{
M M Honeyman, A Green, J B Holton, J V Leonard
}

\begin{abstract}
Ascertainment of cases of classical galactosaemia over a three year period in the UK and the Republic of Ireland, through the British Paediatric Surveillance Unit, identified 58 proved cases and two in whom the diagnosis was strongly suspected. One patient died at 4 days, and severe morbidity was no more frequent in babies diagnosed clinically because of their symptoms compared with those who were screened for galactosaemia. Treatment of four babies in the nonscreened group was delayed until after 5 weeks of age, but it is concluded that all cases of galactosaemia could be diagnosed in an acceptable time without screening, providing clinical vigilance is maintained. (Arch Dis Child 1993; 69: 339-341)
\end{abstract}

Classical galactosaemia is an autosomal recessive disorder of galactose metabolism due to a deficiency of the enzyme galactose-1phosphate uridyl transferase (transferase). Most affected babies develop severe symptoms in the neonatal period and the response to removing galactose from the diet is nearly always dramatic, with resolution of the liver and kidney disease and cataracts. If not treated the babies may die of liver failure and from Gram negative sepsis. In an early study in Los Angeles, ${ }^{1} 59$ index cases of galactosaemia were found to have 13 older siblings who had died with a presumptive diagnosis of the disease, suggesting that often the disorder was not being recognised, and hence had a high mortality of around $20 \%$.

The fact that galactosaemia is a life threatening illness with a high mortality if untreated, combined with optimism about early treatment and long term outcome, has led to the development of many neonatal screening programmes. ${ }^{2}$ Screening, however, may reduce mortality only if carried out very early in life, ${ }^{3}$ and it is possible that sound clinical vigilance could prove as effective. In addition, recent studies show the long term outcome to be no better after early detection and treatment. ${ }^{4}$

The object of this study was to assess the case for introducing neonatal screening for galactosaemia in those areas of the UK that do not screen for this disorder.

\section{Methods}

Starting in January 1988, paediatricians in the UK and the Republic of Ireland were asked to notify any new cases suspected of having galactosaemia through the monthly British Paediatric Surveillance Unit card scheme. Further details of each case were obtained from the notifying paediatrician by means of a questionnaire. In addition, those specialist laboratories who provide a service for transferase assay were contacted annually for details of cases of galactosaemia that they had confirmed during the study period.

\section{Results}

During the period of the study, from 1 January 1988-31 December 1990, 112 cases of suspected galactosaemia were notified. Of these, 58 were confirmed to have classical galactosaemia with absent transferase activity. The diagnosis was strongly suspected in two additional cases who were subsequently included in the study. One of these died of Escherichia coli septicaemia at 4 days of age. Although transferase assay was not performed on this patient, the transferase activity of both parents was within the range of heterozygotes. In the other case, transferase assay was deferred because an exchange transfusion had been done for jaundice and the diagnosis was not subsequently confirmed. The clinical presentation and response to withdrawal of galactose from the diet, however, was consistent with a diagnosis of galactosaemia. Five children with other disorders of galactose metabolism, apart from classical galactosaemia, were also detected by screening laboratories. These were Duarte/galactosaemia compound heterozygotes (two patients), uridine diphosphogalactose-4-epimerase deficiencies (two patients), and galactokinase deficiency (one patient).

Of the 60 patients included in the study, 56 were white. There was one death in this group, that of the patient referred to earlier who died from $E$ coli septicaemia at 4 days. Three siblings of the study patients died of liver disease around 6 weeks of age and were presumed affected. Two came from areas that were being screened at the time of their birth, but it could not be confirmed that neonatal screening had been performed in these cases. The other came from an area not screening for galactosaemia. 
Table 1 An analysis of the year and country of birth in the 60 patients in the study

\begin{tabular}{llllll}
\hline & & \multicolumn{2}{l}{ Not screened $(n=46)$} & & Screened $(n=14)$ \\
& Total & $\begin{array}{l}\text { England, Wales, } \\
\text { Northern Ireland }\end{array}$ & & Scotland & $\begin{array}{l}\text { Republic of } \\
\text { Ireland }\end{array}$ \\
\hline 1988 & 25 & 17 & 2 & 6 \\
1989 & 19 & 16 & 3 & 0 \\
1990 & 16 & 13 & 2 & 1
\end{tabular}

Table 2 Reason given for suspecting the diagnosis of galactosaemia in 60 study patients

\begin{tabular}{llc}
\hline & $\begin{array}{l}\text { Screened } \\
(n=14)\end{array}$ & $\begin{array}{c}\text { Not screened } \\
(n=46)\end{array}$ \\
\hline Screening & 6 & - \\
Family history & 4 & 6 \\
Clinical features & 4 & 12 \\
$\begin{array}{l}\text { Clinical features and biochemical } \\
\text { tests }\end{array}$ & - & $25^{\star}$ \\
Biochemical only & - & $3 \dagger$ \\
\hline
\end{tabular}

^Twenty two patients had positive urinary reducing substances and three a raised phenylalanine on phenylketonuria screening. tThe three patients had raised phenylalanine on phenylketonuria screening.

Table 3 Clinical features of 37 symptomatic cases

\begin{tabular}{ll}
\hline & No (\%) of patients with each feature \\
\hline Jaundice & $33(89)$ \\
Failure to thrive & $11(39)$ \\
Septicaemia & $5(13)^{\star}$ \\
Urinary tract infection & $1(3)$ \\
Hepatomegaly & $6(16)$ \\
Splenomegaly & $2(6)$ \\
Coagulopathy & $3(8)$ \\
Encephalopathy & $1(3)$ \\
Cataracts & $5(13)$ \\
\hline
\end{tabular}

*One patient died.

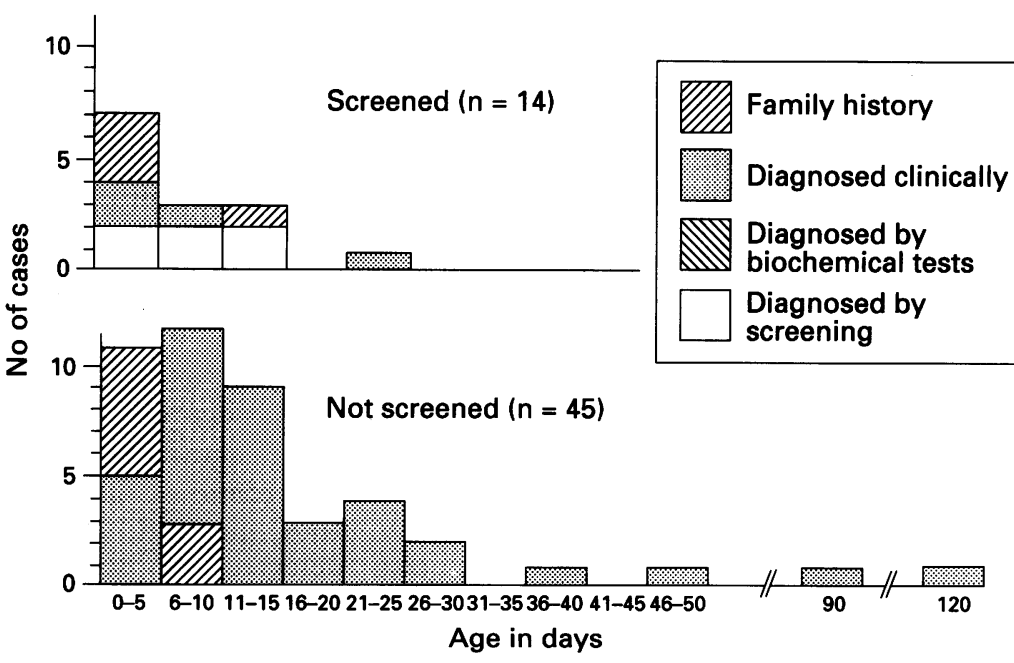

Age at introduction of galactose free diet.

Table 4 Recorded clinical and biochemical details of the late diagnoses

\begin{tabular}{llc} 
Case & Notails & $\begin{array}{l}\text { Diet } \\
\text { started } \\
\text { (days) }\end{array}$ \\
\hline 1 & $\begin{array}{l}\text { Failure to thrive at 1 month, conjugated hyperbilirubinaemia, splenomegaly, } \\
\text { cataracts }\end{array}$ & 38 \\
2 & $\begin{array}{c}\text { Convulsions at 3 months, hepatomegaly, no jaundice, generalised } \\
\text { aminoaciduria, no cataracts noted, cousin with classical galactosaemia but no } \\
\text { parental consanquinity }\end{array}$ & 90 \\
3 & $\begin{array}{c}\text { Failure to thrive from 1 month, recurrent urinary tract infection, diarrhoea and } \\
\text { vomiting, hepatomegaly, cataracts not noted, travelling family }\end{array}$ & 150 \\
4 & Failure to thrive and poor feeding, cataracts, metabolic acidosis
\end{tabular}

Table 1 divides the study patients into three groups on the basis of the place of birth: the three countries of the UK, where there is no neonatal screening for galactosaemia, and Scotland and the Republic of Ireland, where there are screening programmes. From this and birth data the incidence of classical galactosaemia during the study period was 1:44000 in the UK as a whole and 1:23500 in the Republic of Ireland. Table 2 analyses the reasons given for having suspected a diagnosis of galactosaemia in both the non-screened and screened groups. In the former the diagnosis was considered because of clinical features alone in 12 out of 46 cases and because of a combination of both clinical features and biochemical tests in 25 of 46 cases.

The biochemical test that contributed towards the diagnosis most frequently was a positive urinary reducing substance. In addition, three cases were suspected only because of a positive phenylketonuria screening test. In the screened group, clinical features were considered to have contributed to the diagnosis in four out of 14 patients as there is an inevitable delay before the results of the screening are known. The clinical features of the 37 patients in the non-screened group who were symptomatic are shown in table 3. The most frequent presenting feature was jaundice, but nine babies, $20 \%$ of the total non-screened group, were acutely unwell with encephalopathy, coagulopathy, septicaemia, or jaundice severe enough to require exchange transfusion. Four babies of the screened group (28\%) were also acutely unwell before the result of the screening test was known.

The figure shows the age when treatment was started in the two groups in the 59 living cases. Despite a family history in 10 patients, galactose was not excluded from birth in all cases but nine were on the diet by 5 days of age. In one case the diet was not started until 14 days of age, although the baby was screened. In the remaining cases without a family history, nine out of 10 in the screened group were on diet by 15 days. The only exception was caused by a false negative screening test, and the diagnosis was made clinically on day 21 . In the non-screened group a higher proportion of patients did not start treatment until after 15 days ( $29 \%$ compared with $7 \%$ in the screened group). The clinical details of the four patients who were treated late are shown in table 4.

\section{Discussion}

To justify a neonatal screening programme it should lead to earlier diagnosis and treatment of a disease with consequent improvements in mortality, morbidity, and long term outcome.

Early work indicated that there may be considerable neonatal mortality in undiagnosed galactosaemia, ${ }^{1}$ and this remained significant even when screening was introduced. ${ }^{5}$ Very early testing for galactosaemia may prevent neonatal mortality, ${ }^{3}$ but this requires the collection of a separate blood specimen from that taken to screen for phenylketonuria. Little 
significance can be attached to the fact that during the study period only one death occurred in the non-screened group because there was no means of ascertaining all the deaths from galactosaemia. It is notable, however, that this death occurred at 4 days of age and is, therefore, unlikely to have been prevented by screening. The sibling data indicates a lower mortality generally among families in the study compared with the study referred to earlier, ${ }^{1}$ with only one sibling death, presumed due to galactosaemia, in the nonscreened group. On the other hand two sibling deaths were identified in families that were resident in screened populations at the time of death.

Although screening might reduce neonatal morbidity overall, the incidence of severe symptoms was no higher in the non-screened group than in the screened group. Moreover, recent work has shown that long term outlook is not influenced by the severity of neonatal symptoms, ${ }^{4}$ and only if treatment is started after the 65th day is there any significant effect on developmental progress. Treatment was started after this period in two out of 46 babies in the non-screened group.

The accepted criteria for the introduction of a screening programme have only partially been met in the case of galactosaemia. Although screening should lead to earlier diagnosis this has no long term consequences apart from in a minority of cases. These cases should all be under paediatric care and the symptoms point to galactosaemia as a possible diagnosis. Although the incidence in the UK was higher than previously supposed, ${ }^{6}$ and the higher incidence in the Republic of Ireland was confirmed, galactosaemia is a relatively rare disease and screening for it should not take a high priority. The negative effects of a screening programme have also to be considered. It may reduce clinical vigilance and, in consequence lead to the death of a child who becomes acutely ill at a very early age before the screening result is available. A false negative result, which should occur very infrequently but did occur during the study, may delay consideration of the diagnosis with possible harmful consequences.

It is concluded from the study that there is no real justification to introduce galactosaemia screening on a wider scale within the UK. Countries that do not screen for the disease should, however, continue to maintain a high level of awareness of the disease. This is particularly important when there is known to be an increased risk in the family, and it applies even in areas that have a screening programme. Early in the neonatal period, patients may present with a fulminating septicaemic illness with encephalopathy, jaundice, and coagulopathy and if the patient dies there is a risk that the underlying metabolic disorder will not be recognised. More commonly the patients present with jaundice, vomiting, feeding difficulties, and hepatomegaly. Those who present later have a more chronic illness characterised by failure to thrive, with feeding difficulties, development delay, fits, and renal tubular disease. Jaundice may be less prominent but if there is any suspicion of galactosaemia, cataracts should always be sought.

Paediatricians and laboratory scientists should be reminded that a negative result for urinary reducing substances does not exclude galactosaemia, ${ }^{7}$ and an enzyme screening test should be requested if there is a high index of suspicion. ${ }^{8}$ The practice of following up positive phenylketonuria screening tests with sugar chromatography ${ }^{9}$ appears to have been extremely successful in detecting $10 \%$ of the cases in this study, and perhaps the sensitivity and cost effectiveness of this procedure deserves further investigation.

We wish to thank the Research Trust for Metabolic Diseases in Childhood for a grant towards the cost of this project and all the paediatricians and laboratory scientists who collaborated in this study.

1 Donnell GN, Koch R, Fishler K, Ng WG. Clinical aspects of galactosaemia. In: Burman D, Holton JB, Pennock CV, eds. Inherited disorders of carbohydrate metabolism. Lancaster: eds. Inherited disorders of carb

2 Ng WG, Kawamura M, Donnell GN. Galactosaemia screening; methodology and outcome from worldwide data collection. In: Therrell BL, ed. Advances in neonatal screening. Amsterdam: Elsevier, 1987: 243-9.

3 Hayes A, Bowling FG, Fraser D, Krimmer HL, Marriman A, Clague AE. Neonatal screening and an intensive management programme for galactosaemia: early evidence of benefits. Med $\mathcal{F}$ Aust 1988; 149: 21-5.

4 Waggoner DD, Buist NRM, Donnell GN. Long term prognosis in galactosaemia: results of a survey of 350 cases. f Inherited Metab Dis 1990; 13: 802-18.

5 Gill AE, Amador PS. A retrospective study of galactosaemia cases identified through newborn screening in New York State, 1968-1985. In: Therrell BL, ed. Advances in neonatal screening. Amsterdam: Elsevier, 1987: 251-4.

6 Schwarz V, Wells AR, Holzel A, Komrower GM. A study of the genetics of galactosaemia. Ann Hum Genet 1961; 25: 287-90.

7 Monk AM, Mitchell AJH, Milligan DWA, Holton JB. The diagnosis of classical galactosaemia. Arch Dis Child 1977; 52: 943-7.

8 Beutler E, Baluda $M$. A simple spot screening test for galactosaemia. f Lab Clin Med 1966; 68: 137-41.

9 Pollitt RJ, Worthy E, Green A. Galactosaemia detection as a bonus from screening for phenylketonuria. $\mathcal{f}$ Inherited Metab Dis 1982; 5: 51-2. 